\title{
Evaluation of Efficacy of Different Instrumentation for Removal of Gutta-percha and Sealers in Endodontic Retreatment: An In Vitro Study
}

\author{
Pratik Agrawal ${ }^{1}$, Pavithra K Ramanna ${ }^{2}$, Suraj Arora ${ }^{3}$, Sujith Sivarajan ${ }^{4}$, Adarsh Jayan ${ }^{5}$, Kenchappanavar M Sangeetha ${ }^{6}$
}

\begin{abstract}
Aim: The aim of the present study was to evaluate the efficacy of different instrumentation for removal of gutta-percha and sealers in endodontic retreatment.

Materials and methods: A total of single-rooted mandibular premolars were collected. Access opening was performed in all specimens. The working length was determined by reducing $1 \mathrm{~mm}$ from the length of instruments that were seen reaching the apex. All the canals were dried with paper points. Lateral condensation technique was used to obturate the canals with gutta-percha and zinc oxide eugenol was used as a sealer. The specimens were randomly segregated into three experimental groups. Group I: ultrasonic retreatment tip, group II: R-Endo retreatment files, group III: Mtwo retreatment files. Roots were grooved into two halves with a diamond disc in a longitudinal, buccolingual direction. A stereomicroscope with $\times 40$ magnification was used to image the quantity of gutta-percha and sealer on canal walls.

Results: With ultrasonic retreatment tip, least amount $(1.96 \pm 0.32)$ of gutta-percha and sealer remained, followed by Mtwo retreatment files $(2.84 \pm 0.24)$ and R-Endo retreatment files $(3.18 \pm 0.63)$. A statistically significant inter-group difference among different instrumentation groups was demonstrated by ANCOVA analysis.

Conclusion: In the present study, ultrasonic retreatment tip file systems was found to be more effective in the removal of root canal filling material, followed subsequently by Mtwo retreatment file system and R-Endo retreatment file system.

Clinical significance: Thorough removal of filling material from the root canals is essential during root canal retreatment for probable cleaning and shaping of canal morphology. Thus, clinicians should be aware of the suitable and better instrumentation system that provides a clean and sterile root canal system without any debris.
\end{abstract}

Keywords: Endodontic retreatment, Gutta-percha, Sealers, Stereomicroscope.

The Journal of Contemporary Dental Practice (2019): 10.5005/jp-journals-10024-2670

\section{INTRODUCTION}

The key to successful endodontic therapy that lasts over an extended period of time is thorough surgical removal of the root canal system followed by sealing off the canals three-dimensionally. When these goals could not be achieved completely, disease-causing pathogens continue to remain within the canals, finally resulting in failure of endodontic treatment. Nonsurgical retreatment is often considered the treatment of choice in management of failed endodontic cases with a success rate of $74-98 \% .^{1}$ In the course of retreatment procedure, total elimination of root canal filling material is chiefly important so as to gain the actual cleaning and sterilization of root canals. $^{2}$

Sometimes, persistent infection or re-infection of the root canal of a tooth may necessitate retreatment post root canal procedure. Additionally, teeth that have been obturated inadequately, root canals that have been unfilled or untreated, or root fillings that have not been extended completely may need retreatment prior to coronal restoration as otherwise it may result in endodontic failure in future. $^{3}$

The most commonly used root canal filling material is guttapercha along with various sealers. Several drawbacks of guttapercha such as, absence of adhesive property, failure to support the tooth post-obturation, contraction on cooling, hydrophobic nature and insufficient rigidity have led to the development of different obturation materials. ${ }^{4}$
${ }^{1}$ Department of Conservative Dentistry and Endodontics, Kalinga Institute of Dental Sciences, KIIT Deemed to be University, Bhubaneswar, Odisha, India

${ }^{2}$ Department of Prosthodontics, Crown and Bridge, Vydehi Institute of Dental Sciences and Research Hospital, Bengaluru, Karnataka, India ${ }^{3}$ Department of Restorative Dental Sciences, College of Dentistry, King Khalid University, Abha, Kingdom of Saudi Arabia

${ }^{4}$ Department of Orthodontics and Dentofacial Orthopedics, PMS College of Dental Science and Research, Vattappara, Trivandrum, Kerala, India

${ }^{5}$ Department of Conservative Dentistry and Endodontics, PMS College of Dental Science and Research, Vattappara, Trivandrum, Kerala, India

${ }^{6}$ Department of Pedodontics and Preventive Dentistry, SJM Dental College and Hospital, Chitradurga, Karnataka, India

Corresponding Author: Pratik Agrawal, Department of Conservative Dentistry and Endodontics, Kalinga Institute of Dental Sciences, KIIT Deemed to be University, Bhubaneswar, Odisha, India, Phone: +91 8018043808, e-mail: dr.pratikagrawal07@gmail.com

How to cite this article: Agrawal P, Ramanna PK, Arora S, et al. Evaluation of Efficacy of Different Instrumentation for Removal of Gutta-percha and Sealers in Endodontic Retreatment: An In Vitro Study. J Contemp Dent Pract 2019;20(11):1269-1273.

Source of support: Nil

Conflict of interest: None

(c) The Author(s). 2019 Open Access This article is distributed under the terms of the Creative Commons Attribution 4.0 International License (https://creativecommons. org/licenses/by-nc/4.0/), which permits unrestricted use, distribution, and non-commercial reproduction in any medium, provided you give appropriate credit to the original author(s) and the source, provide a link to the Creative Commons license, and indicate if changes were made. The Creative Commons Public Domain Dedication waiver (http://creativecommons.org/publicdomain/zero/1.0/) applies to the data made available in this article, unless otherwise stated. 
Excavation of gutta-percha and sealer from incompetently prepared and obturated root canals are crucial so as to expose the necrotic tissue fragments or residual bacteria that may cause periapical inflammation and failure in the future. Removal of GP can be achieved with the use of manual endodontic files, heatdissipating instruments, rotary instruments or ultrasonics, with or without the aid of solvents. ${ }^{5}$

The use of various techniques such as manual endodontic files, Gates Glidden Burs, heat-dissipating instruments, nickel titanium rotary instruments, ultrasonic instruments, lasers along with different solvents like chloroform, eucalyptus oil, xylene, halothane, turpentine oil, white pine oil and orange oil have all been demonstrated to aid the removal of filling materials from root canal system. ${ }^{6}$

The procedure of endodontic treatment and retreatment may introduce irritants, filling materials, necrotic pulp, or bacteria into the apical region which act as irritants. The consequences of this apical extrusion of debris are postoperative pain and discomfort. These apically extended irritants are clinically responsible for flare ups and inflammation developing postoperatively which ultimately result in an uneventful apical healing. ${ }^{7}$

Retreatment is a time-consuming and an extensive technique leading to many procedural mistakes. Choosing a case for retreatment is a scrupulous process which involves the assessment of both merits and demerits of tooth prognosis. So, the current study was conducted to evaluate the efficacy of various instrumentation procedures along with sealers for the removal of gutta-percha in endodontic retreatment.

\section{Materials and Methods}

The present in vitro study was conducted in the Department of Conservative Dentistry and Endodontics, Kalinga Institute of Dental Sciences, Bhubaneswar.

A total of sixty teeth (Fig. 1) that were extracted for orthodontic purpose were used. The selected teeth were single-rooted mandibular premolars with single root canal having a type I canal configuration and a root curvature of $0^{\circ}-10^{\circ}$. The inclusion criterion was that the tooth had to be extracted at least 3 months prior trial and stored in saline. The exclusion criteria were fractured teeth, teeth having more than one root canal, resorbed teeth, teeth with open apices, carious teeth, obturated teeth, dilacerated teeth. The chosen teeth were disinfected for 1 hour with $0.5 \%$ chloramine-T and stored in saline until use. The teeth were evaluated using radiovisiography (RVG).

\section{Endodontic Therapy}

The coronal half of the included teeth was separated so as to attain a standardized working length of $15 \mathrm{~mm}$. Access opening was gained in all specimens. One millimeter was subtracted from the length of instruments that reached up to the apex to obtain the working length (Fig. 2). ProTaper Universal rotary Ni-Ti instruments were used to perform endodontic treatment. Glydes were used to enlarge the canals for facilitation up to $\mathrm{F} 3$ at working length. About $2.5 \mathrm{~mL}$ of $5.25 \% \mathrm{NaOCl}$ was used to irrigate all canals between each

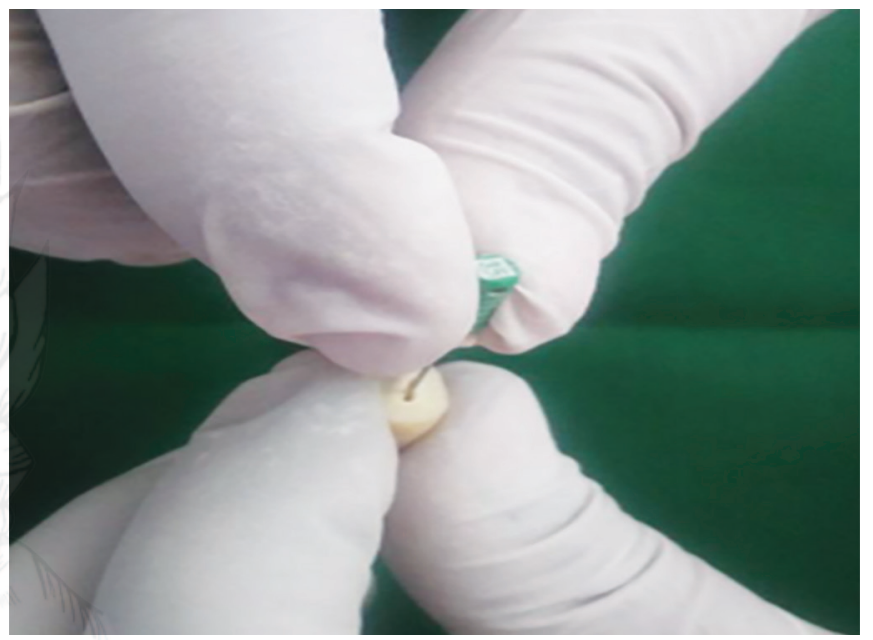

Fig. 2: Initial endodontic therapy

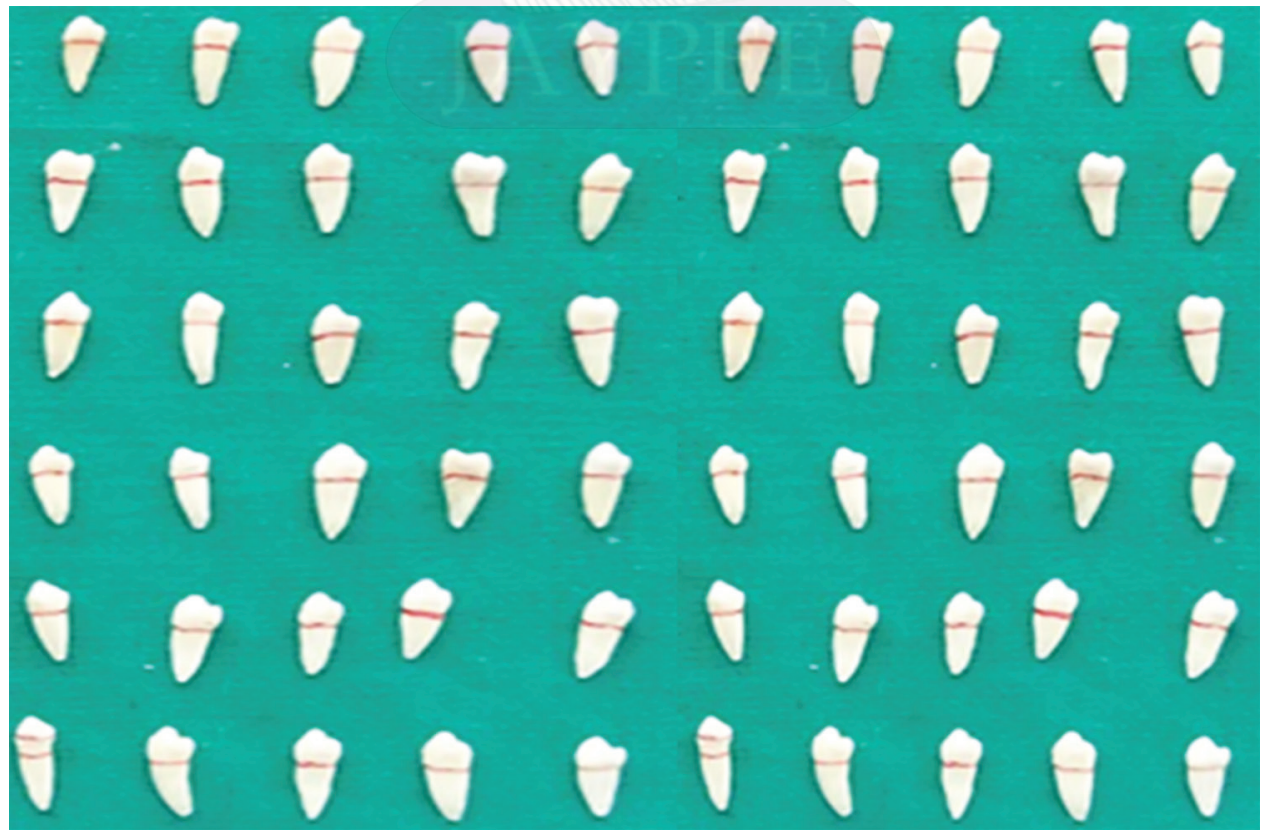

Fig. 1: Samples used in the present study 
instrument change. The canals were finally flushed with $5 \mathrm{~mL}$ of $17 \%$ ethylenediaminetetraacetic acid (EDTA) for 30 seconds. This was followed by a rinse with $5 \mathrm{~mL}$ of saline.

All the canals were dried with paper points. A lateral condensation technique was adapted to obturate the canals with gutta-percha and zinc oxide eugenol sealant. The coronal access cavity was sealed with zinc oxide eugenol cement. Teeth were stored in artificial saliva at $37^{\circ} \mathrm{C}$ for 30 days at $100 \%$ humidity to allow the sealer to set.

\section{Retreatment of Endodontically Treated Teeth}

A diamond disk was used to decoronate the teeth at the cementenamel junction and to leave a root of $15 \mathrm{~mm}$ in length. The specimens were randomly distributed into three experimental groups. The Gates Glidden drill was used to remove the first 2-3 mm of gutta-percha and standard protocol was followed in each technique. ${ }^{6}$

Below are the three experimental groups with 20 teeth in each group:

\section{Group I: Ultrasonic Retreatment Tip}

As the use of ultrasonics in retreatment is actually an unfamiliar territory in endodontics, ultrasonic endodontic retreatment tip E-7 (16 mm length and $0.6 \mathrm{~mm}$ diameter at tip) was used for the removal of root canal filling material. The root canals were irrigated for 10 seconds with $2 \mathrm{~mL}$ of $3 \% \mathrm{NaOCl}$ during retreatment and then with saline after the use of each file. After three uses, files were discarded. After instrumentation, the canals were irrigated with $2 \mathrm{~mL}$ of $17 \%$ EDTA and $5 \mathrm{~mL}$ of distilled water.

\section{Group II: R-Endo Retreatment Files}

Under this group, the canal orifices were located using a RM file. A pathway was also created using RM file. Afterwards, a RE file with circumferential filing towards the apex was used up to a depth of 1-3 mm. After this, a R1 instrument for the coronal third, R2 for the middle and R3 for the apical third were used. A brushing circumferential movement was adapted with all the instruments to remove filling material at a speed of $300 \mathrm{rpm}$. When no obturation material was seen adhering to the retreatment instruments, the preparation was considered to be complete. With every instrument change, the root canals were irrigated using $2 \mathrm{~mL}$ of $3 \% \mathrm{NaOCl}$. The canals were finally irrigated using $2 \mathrm{~mL}$ of $17 \%$ EDTA and $5 \mathrm{~mL}$ of distilled water.

\section{Group III: Mtwo Retreatment Files}

As per manufacturer's recommendation, Mtwo retreatment files were used with short brushing motion along with gentle in-and-out motion with the use of an air-driven rotary handpiece at continuous speed of $300 \mathrm{rpm}$. R1 (size 15; 5\% taper) was initially used up to working length. Soon after that, R2 (size 25; 5\% taper) was used up to the working length. With every instrument change, the root canals were irrigated using $2 \mathrm{~mL}$ of $3 \% \mathrm{NaOCl}$. The canals were finally irrigated using with $2 \mathrm{~mL}$ of $17 \%$ EDTA and $5 \mathrm{~mL}$ of distilled water.

\section{Assessment of Gutta-percha and Sealer Removal}

Roots were grooved into two halves with a diamond disc in a longitudinal, buccolingual direction, such that the groove was in closeness to wall of the root canal but not cutting into the canal wall. After cutting the tooth, each half of every single specimen was imaged separately (Fig. 3). Digitized images of every third of the root canal of each half of every single specimen were acquired at $\times 40$ original magnifications. Standardized imaging techniques were used to image the amount of gutta-percha and sealer sticking on to the canal walls in both halves of the tooth and recorded in square millimeters using the part of image analyzer software [Image-pro Express 6.0 (Media cybernetics)] coupled to $\times 40$ magnification stereomicroscope (Magnus, Olympus India).

\section{Statistical Analysis}

A Statistical Package for Social Sciences (SPSS), version 20 (SPSS Inc., Chicago, IL, USA) was used to enter the collected data. The mean of the remaining obturation material in the apical third, middle third and coronal third was evaluated statistically for all groups. ANOVA test followed by post hoc Tukey's test to demonstrate the significance of the inter-group differences were used to perform statistical analysis.

\section{Results}

The mean and standard deviation of total endodontic material remaining on the entire root canal wall are as shown in Table 1. Lowest amount of gutta-percha and sealer only remained after the use of ultrasonic retreatment tip $(1.96 \pm 0.32)$, subsequently followed by Mtwo retreatment files $(2.84 \pm 0.24)$ and R-Endo retreatment files $(3.18 \pm 0.63)$.

Table 2 demonstrates the comparison of the mean of overall endodontic filling material residues among the three
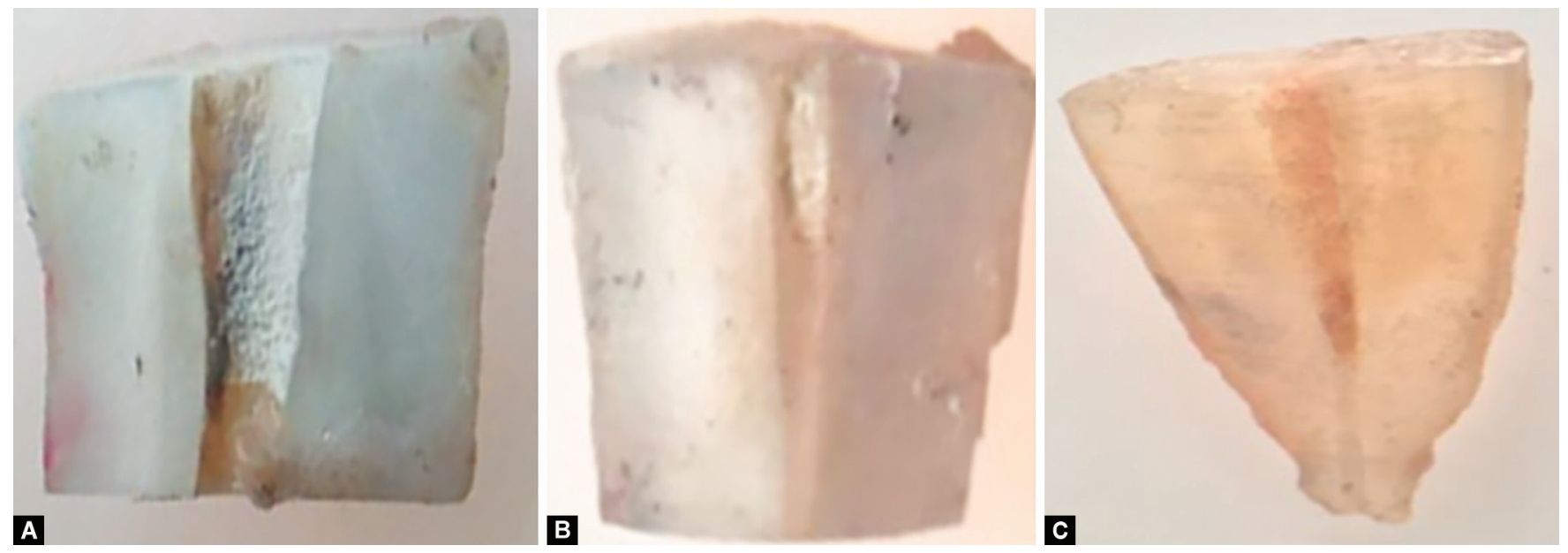

Figs $3 \mathrm{~A}$ to $\mathrm{C}$ : Tooth section: (A) Coronal third; (B) Middle third; (C) Apical third 
Table 1: Mean and standard deviation of total endodontic material remaining on the entire root canal wall

\begin{tabular}{lcc}
\hline Groups & $n$ & Mean \pm std. deviation \\
\hline Group I: ultrasonic retreatment tip & 20 & $1.96 \pm 0.32$ \\
Group II: R-Endo retreatment files & 20 & $3.18 \pm 0.63$ \\
Group III: Mtwo retreatment files & 20 & $2.84 \pm 0.24$ \\
\hline
\end{tabular}

Table 2: Comparison of the mean of total endodontic filling material remaining among the three groups

\begin{tabular}{lllll}
\hline Groups & Mean $\pm S D$ & Fvalue & $p$ value & Significance \\
\hline $\begin{array}{l}\text { Group I: ultrasonic } \\
\text { retreatment tip }\end{array}$ & $1.96 \pm 0.32$ & 24.162 & 0.001 & $\mathrm{HS}$ \\
$\begin{array}{l}\text { Group II: R-Endo } \\
\text { retreatment files }\end{array}$ & $3.18 \pm 0.63$ & & & \\
$\begin{array}{l}\text { Group III: Mtwo } \\
\text { retreatment files }\end{array}$ & $2.84 \pm 0.24$ & & & \\
\hline
\end{tabular}

$p<0.05$; HS, highly significant

Table 3: Multiple comparisons Tukey HSD

\begin{tabular}{llll}
\hline Group & Compared with & Mean difference (I-J) & Sig. \\
\hline Group I & Group II & -1.22 & 0.001 \\
& Group III & -0.88 & 0.04 \\
Group II & Group I & 1.22 & 0.001 \\
& Group III & 0.34 & 0.08 \\
\multirow{3}{*}{ Group III } & Group I & 0.88 & 0.04 \\
& Group II & -0.34 & 0.08 \\
\hline
\end{tabular}

Table 4: Comparison of the mean of total endodontic filling material remaining in the coronal, middle, apical third among the three groups

\begin{tabular}{llll}
\hline $\begin{array}{l}\text { Type of } \\
\text { instrumentation }\end{array}$ & $\begin{array}{l}\text { Coronal (mean } \\
\pm S D)\end{array}$ & $\begin{array}{l}\text { Middle (mean } \\
\pm S D)\end{array}$ & $\begin{array}{l}\text { Apical (mean } \\
\pm S D)\end{array}$ \\
\hline $\begin{array}{l}\text { Ultrasonic tip } \\
\text { R-Endo retreatment } \\
\text { files }\end{array}$ & $0.62 \pm 0.10$ & $0.90 \pm 0.18$ & $0.44 \pm 0.04$ \\
$\begin{array}{l}\text { Mtwo retreatment } \\
\text { files }\end{array}$ & $0.47 \pm 0.09$ & $1.19 \pm 0.42$ & $1.09 \pm 0.26$ \\
K ANOVA value-23.442, $p$ value-0.001 & & \\
\hline
\end{tabular}

groups. Ultrasonic retreatment tip resulted in the lowest residue $(1.96 \pm 0.32)$, immediately followed by Mtwo retreatment files group $(2.84 \pm 0.24)$ and then by $\mathrm{R}$-Endo retreatment files group $(3.18 \pm$ 0.63). Results of ANOVA indicated statistically significant $(p<0.001)$ intergroup differences among the instrumentation groups.

The various comparisons between the different instrumentation groups are as displayed in Table 3. Group I vs group II and group I vs group III demonstrated a statistically significant difference among the instrumentation groups ( $p<0.05)$. However, no significant difference between group II vs group III $(p>0.05)$ was seen.

Table 4 displays the comparison of the mean of total endodontic filling material that was left over in the apical, middle and the coronal third among the three groups. Ultrasonic retreatment tip shows the minimal amount of material remaining at apical third $(0.44 \pm 0.04)$, $\mathrm{R}$-Endo retreatment files. And Mtwo retreatment files shows the minimal amount of material remaining at coronal third $(0.90 \pm 0.68$ and $0.47 \pm 0.09$ ). There was a statistically significant difference $(p=0.001)$ found between the apical, middle and coronal third in the removal of gutta-percha and sealers using endodontic retreatment.

\section{Discussion}

Retreatment of the root canal is a most complex, distinct, and timeconsuming endodontic procedure. The clearance of the obturation material from the root canals is of utmost importance for the remodeling of the root canal system and for the accomplishment of the chosen objectives in endodontic therapy. The most promising effect of endodontic retreatment is to set the root canals absolutely free of filling materials. ${ }^{8}$ Over the past several years, many trials have been conducted to establish and discern novel procedures to obtain a clean and sterile root canal system that is free from residual fillings and micro-organisms. Although the application of rotary instruments to the root canals is fast and easy, efficacious cleaning of the whole root canal system is a great deal. ${ }^{9}$

Numerous devices have been used to remove the filling material from the root canals such as stainless-steel hand files, $\mathrm{Ni}-\mathrm{Ti}$ files, lasers and ultrasonic files. The use of conventional files to remove a well-condensed obturating material has relatively been a tiresome and laborious procedure for the operator and might also lead to endodontic accidents. The super elasticity of $\mathrm{Ni}$-Ti files permits a canal preparation that is fairly centered with moderately less carriage of the canal and a reduced occurrence of canal abnormalities. Moreover, the improved taper preparation enables sufficient irrigation. When involved in a crown-down approach, these files have a superior cutting efficiency and a constant reaming motion. Subsequently, root canal preparations that are round, less straightened and with a reduced amount of apical extrusion are attainable. In spite of better flexibility, $\mathrm{Ni}$-Ti files display persistent difficulty in separating filling materials completely from the canal walls. Mtwo Ni-Ti rotary instrumentation system was demonstrated to be faster and more efficient in removal of obturation material than hand files according to Taşdemir et al. ${ }^{10}$ (the teeth were randomly divided into four groups of 15 specimens each. Removal of gutta-percha was performed with ProTaper, R-Endo, Mtwo and Hedström files) and Bramante et al. ${ }^{11}$ [sixty single-rooted human teeth were taken and randomly allocated to ProTaper UR, MTwo R, hand files $(n=20)]$. These results are similar to those obtained by us in showing the Mtwo files to be more efficient than R-Endo files.

In the present study, we found the ultrasonic retreatment tips to be significantly more efficient in removing the gutta-percha and sealers from the canal than other instrumentation methods. Similar results were obtained by Rached-Júnior et al. ${ }^{12}$ who conducted a study on sixty-four incisors and 16 teeth in each group. The ultrasonic retreatment instrument removed more obturation material from the root canals. This could be explained on the basis that the ultrasonic vibrations emerging from the ultrasonic tip facilitates the dislodgement of filling material from the root canal walls enabling the removal of the sealer. The heat that gets generated by the ultrasonic instrument due to friction results in an additive effect on gutta-percha causing softening and dislocation of gutta-percha from the root canal.

The results obtained by Tambe et al. ${ }^{13}$ found ultrasonic retreatment tip to produce little extrusion. With the activation of files, the fragments of filling material get displaced in the coronal half causing less debris accumulation at the apex. Yet another reason could be the increased diameter along the tip of ultrasonic tip which is more than that of the master apical file's diameter and so the tip may not completely reach the apical area creating less debris extrusion at the apex.

A trial by Kasam and Mariswamy ${ }^{6}$ demonstrated on total 48 extracted mandibular premolars. These were divided into 4 groups, i.e., $\mathrm{H}$ files, safe sided $\mathrm{H}$ files, ProTaper universal retreatment rotary 
system and ultrasonic retreatment tip. They found the ultrasonic tip to remove material from the root canals within a short period of time along with little extrusion at the apex. Here again, the combined actions of ultrasonic vibration and frictional heat enabled the displacement of the filling material and gutta-percha from the walls of the root canal.

Both, R-Endo instrumentation and manual instrumentation have been shown to be equally efficient in removing filling material from curved and straight root canals. As per the manufacturers of R-Endo instruments, this instrument is specially designed for retreatment. It has a triangular cross-section with three cutting edges that are equally spaced. It is machined into a round blank and does not have either a radial land or an active tip. This instrument has adequate rigidity that helps to remove filling material from the root canal. ${ }^{14}$

In a trial conducted by Bhagavaldas et al. ${ }^{3}$ on forty-eight extracted human mandibular first premolars. Samples were then randomly divided into four groups. Group I was retreated with Mtwo Rotary system without solvent, group II was retreated with Mtwo Rotary system with Endosolv $\mathrm{R}$ as the solvent, group III with D-RaCe rotary system without solvent, and group IV with $\mathrm{D}$-RaCe rotary system and Endosolv $\mathrm{R}$ solvent, none of the groups demonstrated complete removal of the filling material. The residual sealer on the walls of the canal might have amplified the zone of remaining material. This is in agreement with a study conducted by Schirrmeister et al. ${ }^{15}$

In another study done by Mollo et al., ${ }^{16} \mathrm{R}$-Endo instrumentation system was found to be superior than Mtwo instrumentation system. This variation could be ascribed to the fact that their study used R-Endo instrumentation system followed subsequently by the use of an ISO 35-sizedHero Shaper file for removal of the obturating material.

Our study was conducted using mandibular premolars having single canal. In future, studies involving teeth with complex anatomy and curved root canals have to be carried out to assess the preservation of canal morphology, efficiency and safety of retreatment procedure.

\section{Conclusion}

In the present study, ultrasonic retreatment tip file system was found to be effective in the removal of root canal filling material followed by Mtwo retreatment file system and R-Endo retreatment file system. Nevertheless, we observed no complete removal of gutta-percha and sealers from root canals in any of the experimental groups.

\section{References}

1. Joseph M, Ahlawat J, et al. In vitro evaluation of efficacy of different rotary instrument systems for gutta percha removal during root canal retreatment. J Clin Exp Dent 2016;8(4):e355-e360. DOI: 10.4317/ jced.52488.
2. Saad AY, Al-Hadlaq SM, et al. Efficacy of two rotary NiTi instruments in the removal of gutta percha during root canal retreatment. J Endod 2007;33:38-41. DOI: 10.1016/j.joen.2006.08.012.

3. Bhagavaldas MC, Diwan A, et al. Efficacy of two rotary retreatment systems in removing Gutta-percha and sealer during endodontic retreatment with or without solvent: A comparative in vitro study. J Conserv Dent 2017;20:12-16. DOI: 10.4103/0972-0707.209075.

4. Al-azzawi AK. The efficiency of ProTaper rotary retreatment files in the removal of two different root filling materials. Mal Dent J 2011;8:237-242.

5. Mushtaq M, Farooq R, et al. Dissolving efficacy of different organic solvents on gutta-percha and resilon root canal obturating materials at different immersion time intervals. J Conserv Dent 2012;15(2): 141-145. DOI: 10.4103/0972-0707.94584.

6. Kasam S, Mariyasamy AB. Efficacy of Different Methods for Removing Root Canal Filling Material in Retreatment - An In-vitro Study. J Clin Diagn Res 2016 Jun;10(6):ZC06-ZC10. DOI: 10.7860/ JCDR/2016/17395.7904.

7. Uezu MK, Britto ML, et al. Comparison of debris extruded apically and working time used by protaper universal rotary and protaper retreatment system during gutta-percha removal. J Appl Oral Sci 2010;18(6):542-545. DOI: 10.1590/S1678-77572010000600002.

8. Cunha RS, De Martin AS, et al. In vitro evaluation of the cleansing working time and analysis of the amount of gutta-percha or resilon remnants in the root canal walls after instrumentation for endodontic retreatment. J Endod 2007;33:1426-1428. DOI: 10.1016/ j.joen.2007.07.004.

9. Fariniuk LF, Westphalen VP, et al. Efficacy of five rotary systems vs manual instrumentation during endodontic retreatment. Braz Dent J 2011;22:294-298. DOI: 10.1590/S0103-64402011000400006.

10. Taşdemir T, Er K, et al. Efficacy of three rotary NiTi instruments in removing gutta-percha from root canals. Int Endod J 2008;41:191-196. DOI: 10.1111/j.1365-2591.2007.01335.x.

11. Bramante CM, Fidelis NS, et al. Heat release, time required, and cleaning ability of MTwo R and ProTaper universal retreatment systems in the removal of filling material. J Endod 2010;36:1870-1873. DOI: 10.1016/j.joen.2010.08.013.

12. Rached-Junior FA, Sousa-Neto MD, et al. Confocal microscopy assessment of filling material remaining on root canal walls after retreatment. Int Endod J 2014;47:264-270. DOI: 10.1111/iej. 12142.

13. Tambe VH, Nagmode PS, et al. Evaluation of the amount of debris extruded apically by using conventional syringe, endovac and ultrasonic irrigation technique: an in vitro study. J Int Oral Health 2013;5(3):63-66.

14. Gergi R, Sabbagh C. Effectiveness of Two Nickel-Titanium Rotary Instruments and A Hand File for Removing Gutta-Percha in Severely Curved Root Canals During Retreatment: An Ex Vivo Study. Int Endod J 2007 July;40(7):532-537. DOI: 10.1111/j.1365-2591.2007. 01254.x.

15. Schirrmeister JF, Meyer KM, et al. Effectiveness of hand and rotary instrumentation for removing a new synthetic polymer-based root canal obturation material (Epiphany) during retreatment. Int Endod J 2006;39:150-156. DOI: 10.1111/j.1365-2591.2006.01066.x.

16. Mollo A, Botti G, et al. Efficacy of two Ni-Ti systems and hand files for removing gutta-percha from root canals. Int Endod J 2012;45:1-6. DOI: 10.1111/j.1365-2591.2011.01932.x. 